\title{
correspondence
}

\section{Allegations against Indian research unit refuted}

SIR,-It was regrettable that Robert Walgate's report of the Pugwash workshop in Delhi (2 March, page 8) gave some credence to the allegations made against the Research Unit on Genetic Control of Mosquitos run in New Delhi by the WHO and Indian Council for Medical Research. The allegations have already been

comprehensively refuted (Nature, 256, $353-357 ; 257,175 ; 258,102 ; \mathrm{New}$ Scientist, 69, 88-89; 69, 528; WHO Chronicle, 30, 131-139). May we repeat that the unit's research had no connection with biological warfare; the releases made were of male mosquitos which do not bite and therefore could not transmit disease. The research was principally on the vector of filariasis, a deforming disease which afflicts eight million people in India. At the time that the unit started its work this was certainly a more prevalent disease in India than malaria. Several months before the storm of press criticism broke the unit's joint Technical Planning and Review Group decided to increase the emphasis on Anopheles work in view of the clear signs of resurgence of malaria in India which were then becoming apparent. Field trials using chemosterilants have been conducted in the United States, notably the USDA Cotton Boll Weevil project (Bull. Ent. Soc. Amer., 19, 218-221). The Indian and foreign scientists in the unit were well aware of the need for precautions in the use of chemosterilants: thorough washing of pupae after treatment was a routine procedure and this ensured that the residues in adult Culex fatigans were so low as to be undetectable by gas liquid chromatography (Bull Wld. Hlth Org. 47, 675).

In one sense the falsity of the allegations is less important than the question why they were made and believed by many. One should recall that in the era of Watergate it was fashionable for journalists to 'discover' fiendish CIA-related plots. Unfortunately the Delhi journalists did not take the same care as Woodward and Bernstein to check the facts, the coherence of their story, or the credibility of their sources. Every claim made by the journalists was eagerly believed, and indeed embellished, by the Indian Parliamentary Public Accounts Committee (PAC), whose attitude of mind is illustrated by the fact that they published two sensational 200-page reports about the unit without taking evidence from any of its staff members or visiting the unit, which was

situated in the same city as themselves.

The unit was highly productive of scientific data: 88 papers have so far been published on its work predominantly under Indian authorship (which disposes of the allegation by the PAC that the work was conducted in "total secrecy" and indicates that it is certainly not true of this unit that "The third world scientists involved are left untrained, and when the visiting team withdraws it takes its data with it"). The unit's fate and the Indian government's present attitude to scientific collaboration is indeed a severe setback to hopes for the application of modern biology to the solution of some of the problems of disease and hunger in the third world. The allegations could and should have been refuted as soon as they were made. The only lesson for the future is that administering authorities must face up to a prolonged and concerted campaign of this kind and not keep quiet and hope that it will all blow over.

Ross Institute of Tropicai HuRTIS London, UK

$$
\text { C. F. Curtis }
$$

R. C. von Borstel

National Institute for Medical Research, Mill Hill, London, UK

\section{Nature and nurture}

SIR,--Many of the letters (6 April, page 490, 13 April, page 576) in response to mine (16 March, page 204) were wholly as expected. Evidently repeated exposures of the lack of scientific value of the arguments (Schwartz and Schwartz Nature 248, 84, 1974; 255, 420, 1975) are brushed aside. What, however, did astonish me was the eagerness with which people ascribed the DDR's sporting successes to their selection and training of promising youngsters. Of course this is well known, but precisely the same happens everywhere (though perhaps with some variations of emphasis) in the intellectual and academic spheres. But in both sport and academic achievement, this factor is just part of the environment. Thus my inference is strengthened, not weakened, by this point. Hermann Bondi

Department of Energy,

London, UK

\section{Statistician's plight}

Sir, - I have been asked to draw the attention of scientific colleagues to the plight of Argentinian statistician Carlos Noriega, whose whereabouts are unknown following his arrest in February 1977. A group of statisticians working in the United Nations is requesting help in obtaining information. Readers of Nature may wish to petition the Argentinian government on his behalf.

Royal Statistical Society, H. P. WYNN London, UK

\section{Methyl mercury and safety}

SiR,--Methyl mercuric hydroxide has recently been employed in agarose gel electrophoresis of nucleic acids because it is the best available denaturing agent $t^{1-3}$. We measured release of methyl mercury from agarose gels during preparation, electrophoresis and when localised heating was induced by cutting the gel. We found that toxic to lethal levels of methyl mercury can be released into the laboratory environment. Unless full precautions are taken Minimata disease will probably appear among the operators of the technique.

For these experiments we used the buffer system described by Bailey and Davidson ${ }^{1}$ and an open horizontal gel ${ }^{4}$. This allowed us to study methyl mercury release from the exposed gel surface. Methyl mercury was determined using a Pharmacia mercury detector.

Our experiments reveal three points during electrophoresis when health could be endangered. The first is during addition of methyl mercury to the molten gel $\left(2.3 \mathrm{mg} \mathrm{m} \mathrm{m}^{-3}\right.$ released) and during casting of a gel (1.1 $\mathrm{mg} \mathrm{m}^{-3}$ released). The second is during the first $10 \mathrm{~min}$ of current flow $\left(0.19 \mathrm{mg} \mathrm{m}^{-3}\right.$ released). The third is when localised heating results from breaks or imperfections in the gel ( 4 to $8 \mathrm{mg} \mathrm{m}^{-3}$ released). Methyl mercury release is negligible during all other phases of the operation.

$70-90 \%$ of organic mercury inhaled is delivered to the bloodstream ${ }^{5}$. A body burden of $25 \mathrm{mg}$ of methyl mercury is generally the level at which noticeable symptoms appear. These symptoms include permanent central nervous system damage. Death generally follows accumulations greater than $200 \mathrm{mg}$, but as in the case of the early symptoms there can be a delay of weeks following exposure before the damage is fully expressed ${ }^{6}$.

A single exposure would not exceed $0.4 \mathrm{mg}$ ingested methyl mercury under the most extreme conditions. Unfortunately, the half-life for methyl-mercury retention in the human body is more than 70 days. Thus, large numbers of experiments during a one or two month period could lead to body accumulations more than sufficient to produce symptoms of Minimata disease.

We suggest the following precautions:

- All work with methyl mercury should be confined to a well-vented laboratoryhood equipped with back-up power in case of power failure.

- Handling and disposal of waste materials should be conducted with the care given volatile radioactive compounds. - Operators of the technique should be tested regularly for blood mercury levels. - Pregnant women should not work in laboratory rooms where methyl mercury gels are prepared, as birth defects may be caused by low levels of the compound.

- Journal editors should make an effort to ensure that all papers describing work with toxic materials refer to the materials' abilities to pollute the laboratory environment.

\section{J. E. Cummins} B. E. NESBITT

University of Western Ontario,

London, Ontario, Canada.

Bailey J. M. \& Davidson, N. Analyt. Biochem. 70, 75.85 (1976).

2. Birg $\mathrm{F}$ Favalors $\mathrm{J}$ \& $\mathrm{X}$ amen $\mathrm{K}$ Proc natn Acad SCi U S A 74, 3138-3142 (1977)

3. Frankham $R$ Briscoe D \& Nurthen, $R$ Nature 272 81-83 (1978).

Nature 272, Molec. Miol. 110, 119-146 (1977).

Clarkson, T CRC' Critical Reviews in Toxicology 222-224 (1972).

Harada M Minimata (eds Smith, E. \& Smith A.) $180-192$ (Holt, Rinehard and Winston, N.Y., 1975). 